\title{
Multimetal organic frameworks as drug carriers: aceclofenac as a drug candidate
}

This article was published in the following Dove Press journal:

Drug Design, Development and Therapy

\author{
Muder Al Haydar ${ }^{1,2}$ \\ Hussein Rasool Abid Ab $^{3,4}$ \\ Bruce Sunderland ${ }^{5}$ \\ Shaobin Wang ${ }^{6}$
}

'Pharmaceutics Department, College of Pharmacy, University of Kerbala, Kerbala, Iraq; ${ }^{2}$ Pharmaceutics Department, School of Pharmacy, Faculty of Health Sciences, Curtin University, Perth, WA, Australia;

${ }^{3}$ Department of Chemical Engineering, Curtin University, Perth, WA,

Australia; ${ }^{4}$ Environmental Health Department, College of Applied Medical Sciences, University of Kerbala, Kerbala, Iraq; ${ }^{5} \mathrm{School}$ of Pharmacy, Faculty of Health Sciences, Curtin University, Perth, WA,

Australia; ${ }^{6}$ Department of Chemical Engineering, School of Chemical and Petroleum Engineering, Faculty of Science and Engineering, Curtin University, Perth, WA, Australia
Correspondence: Muder Al Haydar Pharmacy and Biomedical Sciences School, Kent Street, Bentley, Perth, WA 6102, Australia

Tel +6I 892665309

Fax +6I 892662769

Email muder.alhaydar@curtin.edu.au
Background: Multimetal organic frameworks (M-MOFs) were synthesized by including a second metal ion with the main base metal in the synthesis process to enhance their applications for drug delivery. Aceclofenac (ACF), a nonsteroidal anti-inflammatory analgesic drug of low aqueous solubility, was selected as a candidate for the drug delivery system

Purpose: This study aimed to evaluate the loading capacity (LC) and entrapment efficiency (EE) percentages of multi-Material of Institute Lavoisier (MIL)-100(Fe) (M-MIL-100(Fe)) for ACF. Materials and methods: Hydrothermal synthesis procedure was used to prepare multi-MIL100(Fe) samples (Zn I-MIL-100(Fe), Zn II-MIL-100(Fe), Ca I-MIL-100(Fe), Ca II-MIL-100(Fe), Mg I-MIL-100(Fe), Mg II-MIL-100(Fe), Mn I-MIL-100(Fe), and Mn II-MIL-100(Fe)). The characterization of M-MIL-100(Fe) samples was evaluated by X-ray powder diffraction (XRD), Fourier transform infrared spectra, scanning electron microscope (SEM), TGA, and $\mathrm{N}_{2}$ adsorption isotherms. The LC of M-MIL-100(Fe) and EE of ACF were determined. Nuclear magnetic resonance (NMR) and zeta-potential analyses were employed to confirm qualitatively the drug loading within M-MIL-100(Fe).

Results: The ACF LC of MIL-100(Fe) was 27\%, whereas the LC of M-MIL-100(Fe) was significantly increased and ranged from $37 \%$ in Ca I-MIL-100(Fe) to about 57\% and 59\% in Mn II-MIL100(Fe) and Zn II-MIL-100(Fe), respectively. The ACF@M-MOFs release profiles showed slow release rates in phosphate buffer solutions at pH 6.8 and 7.4 as compared to the ACF@MIL-100(Fe). Conclusion: Therefore, M-MOFs showed a significant potential as a carrier for drug delivery systems.

Keywords: aceclofenac, Mixed metal-MOF, MIL-100, drug delivery, drug loading

\section{Introduction}

The use of distinct molecular units in the assembly of extended networks has importance in porous metal organic framework (MOF) materials because they have large surface areas, tunable pore sizes, and pore volumes. ${ }^{1}$ Nowadays, gas storage and drug delivery systems are among the most identified applications of MOFs in the industrial and research fields. ${ }^{2-4}$ MOFs have been employed as drug carriers for more than a decade owing to their advantageous properties. ${ }^{5}$ Currently, the most biocompatible metal is iron, which has been employed in the synthesis of different types of MOFs such as MIL100(Fe). ${ }^{4,6}$ Employing a pure organic linker or one metal in constructing traditional MOFs is regarded as immobilizing functional sites. However, mixed or multi-MOFs (M-MOFs) are utilized to coordinate further metal ions, which can generate improvement in the pore size and surface area of such materials. This can also immobilize different metal sites such as catalytically active sites or open metal sites for their functional properties. ${ }^{4,5}$ 
M-MOFs are usually synthesized by adding further metals in the main structure by a direct synthesis or postsynthesis procedures. $^{7}$ The direct synthesis strategy can be achieved by replacing one organic linker by a corresponding derivative ${ }^{8}$ or by employing two different metals that have the same Coulombic charge, ionic radius, and behavior in order to increase the chances of having simultaneous and homogeneous co-incorporation of the two metals. ${ }^{9}$ The postsynthesis strategy is based on the partial replacement of the metal or partial replacement of the linker. ${ }^{10}$

These materials have demonstrated a high drug loading and controlled release of loaded drugs. ${ }^{11}$ A well-regulated drug delivery system is important to diminish side effects and improve the therapeutic efficacy of drugs. Furthermore, researchers have made significant improvement in the field of drug delivery by MOFs, owing to their simplistic synthesis on a nanoscale and different functional group insertion and surface chemistry. ${ }^{12}$ Drug loading can be achieved by three strategies according to the location of the pay-load and payload-carrier interactions: an encapsulation strategy, direct assembly strategy, and postsynthesis strategy. ${ }^{13}$ Sun et al have proven that mixed ligand MOFs-2 showed the best performance in transporting doxorubicin drug as the consequence of highest loading efficiency even at 48 hours. ${ }^{47}$

Aceclofenac (ACF) is classified as nonsteroidal antiinflammatory drug, as shown in Figure 1. It has poor water solubility $(0.058 \mu \mathrm{g} / \mathrm{mL})^{14}$ and high permeability, which is regarded as class II according to the biopharmaceutics classification system. ${ }^{15}$ It is widely used to relieve pain and reduce inflammation. The major obstacle for its optimum bioavailability is its intrinsic properties such as poor solubility ${ }^{16}$ and kinetic release profile. Different drug delivery systems have been employed to improve ACF bioavailability, enhance

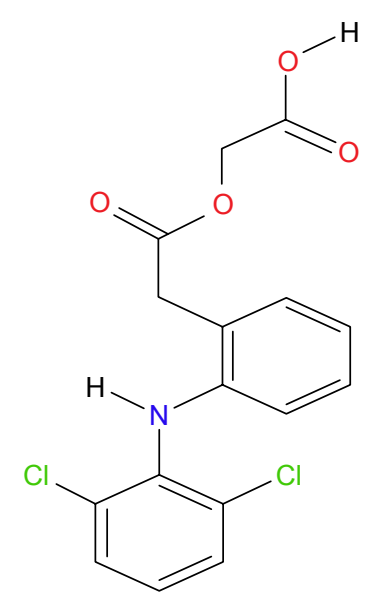

Figure I The chemical structure of aceclofenac. its therapeutic efficacy, and prolong its release. ${ }^{17-20}$ The drug-loading and drug-release processes are mainly ruled by structural parameters of carriers and drug as well as their hydrophobic and hydrophilic properties. ${ }^{21}$

Controlled drug release systems with appropriate carriers, which include liposomes, dendrimers, micro sponges, microparticles, and micelles, have been employed to increase the therapeutic effectiveness and minimize the side effects of low water-soluble drugs. Several undesired adverse effects, which are accompanied with ACF oral administration, such as gastrointestinal tract (GIT) irritation, ulceration, and bleeding, ${ }^{22}$ are leading the researchers to develop a new drug delivery system to reduce such adverse effects.

In this study, eight samples of M-MIL-100(Fe), Zn I-MIL-100(Fe), Zn II-MIL-100(Fe), Ca I-MIL-100(Fe), Ca II-MIL-100(Fe), Mg I-MIL-100(Fe), Mg II-MIL-100(Fe), Mn I-MIL-100(Fe), and Mn II-MIL-100(Fe) were synthesized, characterized, and evaluated for their application as a drug delivery system to evaluate the loading capacity (LC) of M-MIL-100(Fe) for ACF and define M-MIL-100(Fe) as a potential drug delivery system for ACF.

\section{Materials and methods \\ Materials}

ACF was purchased from Thermo Fisher Scientific, Waltham, MA, USA. All chemicals such as iron chloride hexahydrate $\left(\mathrm{FeCl}_{3} \cdot 6 \mathrm{H}_{2} \mathrm{O}\right)$, benzene-1,3,5-tricarboxylic acid $\left(\mathrm{H}_{2} \mathrm{BTC}\right.$, $\left.\mathrm{C}_{9} \mathrm{H}_{6} \mathrm{O}_{6}\right)$, zinc nitrate hexahydrate $\left(\mathrm{Zn}\left(\mathrm{NO}_{3}\right)_{2} \cdot 6 \mathrm{H}_{2} \mathrm{O}\right)$, calcium nitrate tetra hydrate $\left(\mathrm{Ca}\left(\mathrm{NO}_{3}\right)_{2} \cdot 4 \mathrm{H}_{2} \mathrm{O}\right)$, magnesium chloride hexahydrate $\left(\mathrm{MgCl}_{2} \cdot 6 \mathrm{H}_{2} \mathrm{O}\right)$, and manganese chloride hexahydrate $\left(\mathrm{MnCl}_{2} \cdot 6 \mathrm{H}_{2} \mathrm{O}\right)$ were supplied by Sigma-Aldrich Co. (St Louis, MO, USA) and used without further purification. Ethanol $\left(\mathrm{C}_{2} \mathrm{H}_{6} \mathrm{O}>95 \%\right)$ was purchased from Sigma Aldrich and used without further purification. Acetonitrile $\left(\mathrm{C}_{2} \mathrm{H}_{3} \mathrm{~N}\right.$ $99.9 \%)$ and phosphoric acid $\left(\mathrm{H}_{3} \mathrm{PO}_{4} 85 \%\right)$ were supplied from Fisher Scientific, Merelbeke, Belgium.

\section{Synthesis of M-MIL-I00(Fe)}

A hydrothermal synthesis procedure was used to prepare the M-MIL-100(Fe) samples (Zn I-MIL-100(Fe), Zn II-MIL100(Fe), Ca I-MIL-100(Fe), Ca II-MIL-100(Fe), Mg I-MIL100(Fe), Mg II-MIL-100(Fe), Mn I-MIL-100(Fe), and Mn II-MIL-100(Fe)). Symbols I and II refer to the different ratio of a second metal to the iron ion in MIL-100(Fe). The MIL-100(Fe) was prepared by mixing $53.38 \mathrm{mmol}$ of $\mathrm{FeCl}_{3} \cdot 6 \mathrm{H}_{2} \mathrm{O}$ with $23.98 \mathrm{mmol}$ of $\mathrm{H}_{3} \mathrm{BTC}$ (trimesic acid) in $36 \mathrm{~mL}$ of distilled water inside an autoclave (Teflon-lined 
autoclave - 4744 acid digestion bomb - $125 \mathrm{~mL}$ ) and heated in an oven at $433 \mathrm{~K}$ for 15 hours. Then cooled solution was centrifuged and the solid was washed successively in hot water ( $350 \mathrm{~mL}, 343 \mathrm{~K}$, and 3 hours) and in hot ethanol (250 mL, $338 \mathrm{~K}$, and 3 hours). M-MIL-100(Fe) samples were synthesized according to the above procedure using the amount and type of the second metals as described in Table 1. The salt of a second metal was added to the well mixed solution of parent precursors $\left(\mathrm{FeCL}_{3} \cdot 6 \mathrm{H}_{2} \mathrm{O}\right.$ and $\left.\mathrm{H}_{3} \mathrm{BTC}\right)$ in $\mathrm{H}_{2} \mathrm{O}$, then continuously mixed for around 30 minutes. Finally, the solution was transferred to the autoclave and heated in the oven at $433 \mathrm{~K}$ for 15 hours; after that, the crystalline product was washed as described above for as synthesized MIL-100(Fe). The obtained orange-brownish powder was dried at $363 \mathrm{~K}$ overnight and heated under vacuum at $433 \mathrm{~K}$ for 12 hours. $^{23}$

\section{Characterization}

X-ray powder diffraction (XRPD) was performed using a D8 Advance (Bruker AXS, Karlsruhe, Germany), with a copper $\mathrm{K} \alpha$ radiation source ( $40 \mathrm{kV}$ and $40 \mathrm{~mA}$ ) with a Lynx Eye detector. The 2-theta scan range was $5^{\circ}-20^{\circ}$. NMR spectroscopy (Bruker Advance III $400 \mathrm{MHz}$ spectrometer (Germany) with BBFO Plus multi-nuclei probe and low and high temperature capability). Nuclear magnetic resonance (NMR) spectra were referenced to their solvents: deuterium oxide $\left(\mathrm{D}_{2} \mathrm{O}, 1 \mathrm{H}, \delta 4.79 \mathrm{ppm}\right)$. Textural properties of M-MIL$100(\mathrm{Fe})$ were characterized by $\mathrm{N}_{2}$ adsorption-desorption isotherms, which were obtained at $77 \mathrm{~K}$ using a micromeritics, TriStar-3020 instrument, to determine the specific surface area, pore size, and volume. In brief, a $100 \mathrm{mg}$ of the sample was first dried at $373 \mathrm{~K}$ in an oven and then it was degassed by Vac Prep ${ }^{\text {TM }} 061$ at $433 \mathrm{~K}$ overnight. Finally, the degassed sample was used in the TriStar instrument for analysis after getting the net weight of the sample. Fourier transform infrared spectra (FTIR) were obtained using a PerkinElmer FTIR spectrometer in the range of $650-4,000 \mathrm{~cm}^{-1}$. The morphological description was achieved by using a Zeiss Neon 40EsB FESEM. Zeta potential was determined by a Zeta sizer Nano-ZS (Malvern Instruments, Malvern, UK) at $298 \mathrm{~K}$. More specifically, the materials were mixed with distilled water and stirred for 1 hour to be suspension system at constant temperature $(298 \mathrm{~K})$ and then was examined.

\section{Loading of ACF with M-MIL-I 00(Fe)}

The ACF calibration assay was analyzed by HPLC (Shimadzu $20 \mathrm{AC}$ ), and the mobile phase was $50 \mathrm{mmol}$ phosphate buffer solution at $\mathrm{pH} 6.8$ with acetonitrile $30 \%$ at a range of ACF concentrations $(10,20,30,40,50$, and $60 \mu \mathrm{g} / \mathrm{mL})$ in ethanol (95\%). The L-max was 274 and the flow rate was $1.5 \mathrm{~mL} / \mathrm{min}$.

A sample of $40 \mathrm{mg}$ of ACF was dissolved in $10 \mathrm{~mL}$ of $60 \%$ ethanol to make solution of $4 \mathrm{mg} / \mathrm{mL}$ and analyzed by HPLC to determine the amount of ACF before loading. A sample of $40 \mathrm{mg}$ of predried M-MIL-100(Fe) at $393 \mathrm{~K}$ for 6 hours was loaded in the ACF solution in $20 \mathrm{~mL}$ glass containers. After sealing the container tightly, the mixture was stirred (at $150 \mathrm{rpm}$ ) for 24 hours at room temperature by a magnetic stirrer. The supernatant was collected after centrifugation (4,000 rpm, 15 minutes), diluted, and analyzed by HPLC to determine the remaining amount of ACF in the solution after loading. The remaining solid material in the

Table I Materials and the ratio of metal ions used in the M-MIL-I00(Fe) synthesis

\begin{tabular}{|c|c|c|c|}
\hline M-MOF & Metal-based materials & Amount used in the synthesis & Molar ratio\% $\left(\mathrm{M}^{2+} / \mathrm{Fe}^{3+}\right)$ \\
\hline Zn I-MIL-I00(Fe) & $\begin{array}{l}\mathrm{FeCl}_{3} \cdot 6 \mathrm{H}_{2} \mathrm{O} \\
\mathrm{Zn}\left(\mathrm{NO}_{3}\right)_{2} \cdot 6 \mathrm{H}_{2} \mathrm{O}\end{array}$ & $\begin{array}{l}14.43 \mathrm{~g}(53.3 \mathrm{mmol}) \\
\mathrm{l} .59 \mathrm{~g}(5.3 \mathrm{mmol})\end{array}$ & 9.9 \\
\hline Zn II-MIL-100(Fe) & $\begin{array}{l}\mathrm{FeCl}_{3} \cdot 6 \mathrm{H}_{2} \mathrm{O} \\
\mathrm{Zn}\left(\mathrm{NO}_{3}\right)_{2} \cdot 6 \mathrm{H}_{2} \mathrm{O}\end{array}$ & $\begin{array}{l}10.50 \mathrm{~g}(38.0 \mathrm{mmol}) \\
7.94 \mathrm{~g}(26.6 \mathrm{mmol})\end{array}$ & 70 \\
\hline Ca I-MIL-I00(Fe) & $\begin{array}{l}\mathrm{FeCl}_{3} \cdot 6 \mathrm{H}_{2} \mathrm{O} \\
\mathrm{Ca}\left(\mathrm{NO}_{3}\right)_{2} \cdot 4 \mathrm{H}_{2} \mathrm{O}\end{array}$ & $\begin{array}{l}10.70 \mathrm{~g}(39.9 \mathrm{mmol}) \\
1.26 \mathrm{~g}(5.3 \mathrm{mmol})\end{array}$ & 13.2 \\
\hline Ca II-MIL-100(Fe) & $\begin{array}{l}\mathrm{FeCl}_{3} \cdot 6 \mathrm{H}_{2} \mathrm{O} \\
\mathrm{Ca}\left(\mathrm{NO}_{3}\right)_{2} \cdot 4 \mathrm{H}_{2} \mathrm{O}\end{array}$ & $\begin{array}{l}10.69 \mathrm{~g}(39.5 \mathrm{mmol}) \\
6.29 \mathrm{~g}(26.6 \mathrm{mmol})\end{array}$ & 67.3 \\
\hline Mg I-MIL-I00(Fe) & $\begin{array}{l}\mathrm{FeCl}_{3} \cdot 6 \mathrm{H}_{2} \mathrm{O} \\
\mathrm{Mgcl}_{2} \cdot 6 \mathrm{H}_{2} \mathrm{O}\end{array}$ & $\begin{array}{l}14.43 \mathrm{~g}(53.3 \mathrm{mmol}) \\
\mathrm{I} .22 \mathrm{~g}(6.0 \mathrm{mmol})\end{array}$ & 11.2 \\
\hline Mg II-MIL-I00(Fe) & $\begin{array}{l}\mathrm{FeCl}_{3} \cdot 6 \mathrm{H}_{2} \mathrm{O} \\
\mathrm{Mgcl}_{2} \cdot 6 \mathrm{H}_{2} \mathrm{O}\end{array}$ & $\begin{array}{l}10.45 \mathrm{~g}(38.6 \mathrm{mmol}) \\
6.10 \mathrm{~g}(30.0 \mathrm{mmol})\end{array}$ & 77.7 \\
\hline Mn I-MIL-I00(Fe) & $\begin{array}{l}\mathrm{FeCl}_{3} \cdot 6 \mathrm{H}_{2} \mathrm{O} \\
\mathrm{MnCl}_{2} \cdot 6 \mathrm{H}_{2} \mathrm{O}\end{array}$ & $\begin{array}{l}\text { l } 4.43 \mathrm{~g}(53.3 \mathrm{mmol}) \\
\mathrm{l} .22 \mathrm{~g}(5.0 \mathrm{mmol})\end{array}$ & 9.4 \\
\hline Mn II-MIL-I00(Fe) & $\begin{array}{l}\mathrm{FeCl}_{3} \cdot 6 \mathrm{H}_{2} \mathrm{O} \\
\mathrm{MnCl}_{2} \cdot 6 \mathrm{H}_{2} \mathrm{O}\end{array}$ & $\begin{array}{l}10.45 \mathrm{~g}(38.6 \mathrm{mmol}) \\
6.10 \mathrm{~g}(26 \mathrm{mmol})\end{array}$ & 67.3 \\
\hline
\end{tabular}

Abbreviation: M-MOF, multimetal organic framework. 
bottom of the centrifuge tube was dried overnight at $333 \mathrm{~K}$ in an oven. The loading amount of ACF was calculated by subtracting the amount of ACF in the supernatant solution from the amount of ACF before loading. The entrapment efficiency (EE), which is the percentage adsorbed at the surface of M-MIL-100(Fe), was determined using Equation 1

$$
\% \mathrm{EE}=\frac{\text { Weight-loaded ACF }(\mathrm{mg})}{\text { ACF before loading }(\mathrm{mg})} \times 100
$$

The LC of M-MOFs was calculated by employing Equation 2

$$
\% \mathrm{LC}=\frac{\text { Weight-loaded ACF }(\mathrm{mg})}{\text { Weight of loaded } \mathrm{M}-\mathrm{MOF}(\mathrm{mg})} \times 100
$$

\section{ACF release profiles}

Release profiles used a dissolution tester (Erweka DT6 unit). A predetermined quantity of loaded M-MIL-100(Fe) accurately weighed was submerged into $1,000 \mathrm{~mL}$ of
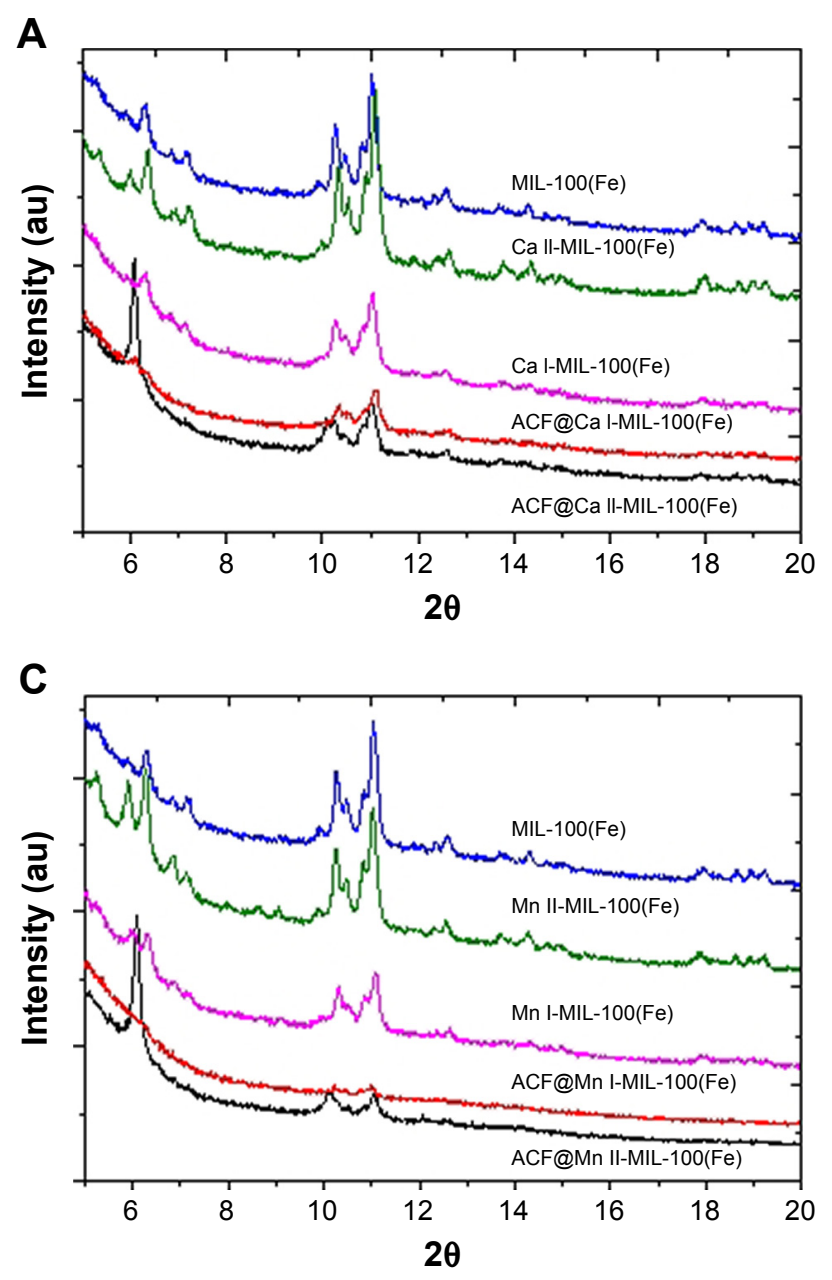

dissolution medium (50 mmol PBS at either $\mathrm{pH} 7.4$ or 6.8 in the dissolution vessel maintained at $37^{\circ} \mathrm{C} \pm 1^{\circ} \mathrm{C}$ with constant stirring at $75 \mathrm{rpm})$. At predetermined time intervals $(0.25$, $0.5,1.5,4,5,6,12,24,30,48$, and 72 hours), an aliquot of $5 \mathrm{~mL}$ was withdrawn and replaced with the same volume of fresh dissolution medium. The aliquots were diluted and filtered by $0.2 \mu \mathrm{m}$ syringe filter and analyzed using HPLC. All experimental results were triplicate and the standard deviation was calculated. A correction of the ACF amount in dissolution medium extracted was calculated regarding the ACF lost in each aliquot. The released percentage of ACF was calculated according to Equation 3

$$
\text { Release }=\frac{\text { Actual ACF released at any time }(\mathrm{mg})}{\text { Theoretical ACF amount loaded }(\mathrm{mg})} \times 100
$$

\section{Results and discussion}

Figure 2A-D shows XRPD profiles for loaded and unloaded M-MIL-100. Diffraction profiles of M-MIL-100(Fe) and
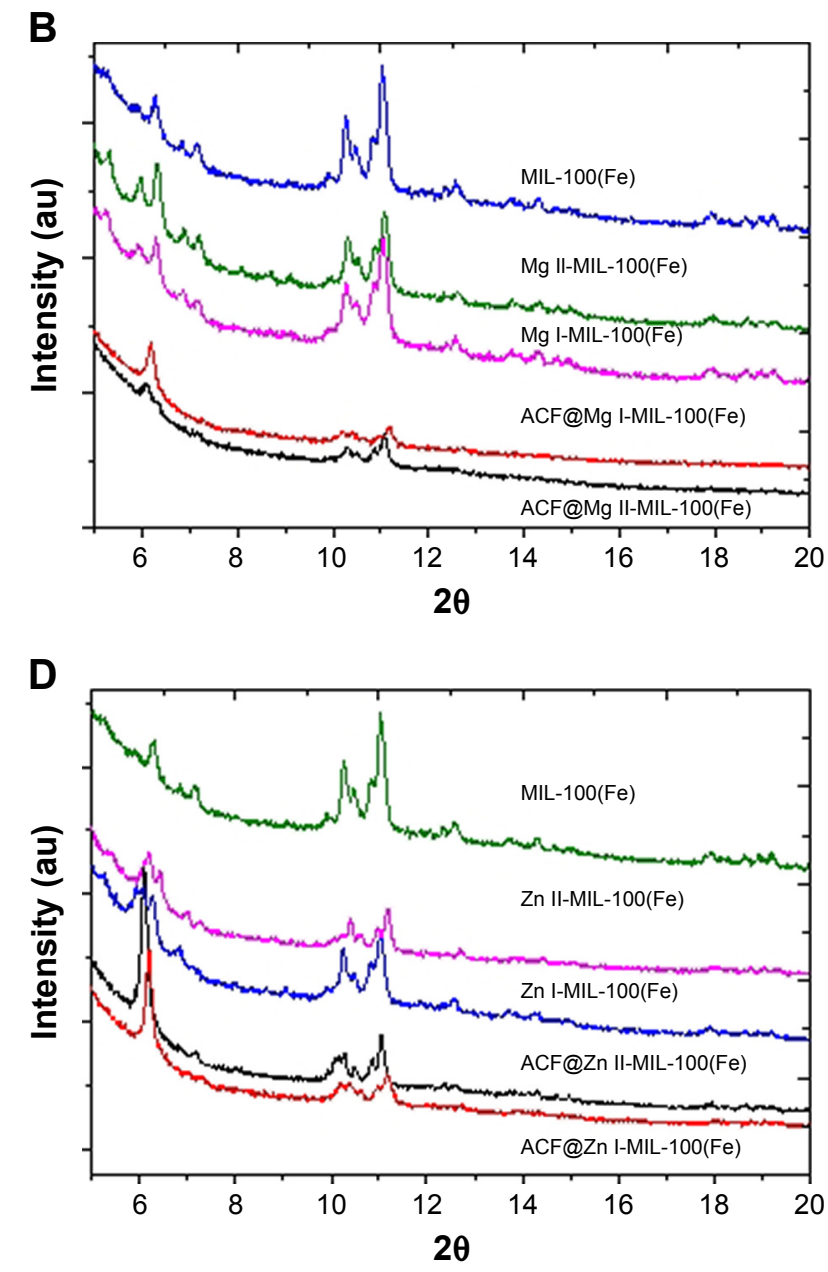

Figure 2 XRPD of MIL-I00(Fe) and M-MIL-100(Fe) samples (where M is either Ca (A), Mg (B), Mn (C), or Zn (D)). Abbreviation: XRPD, X-ray powder diffraction. 
ACF@M-MIL-100(Fe) samples had similar structures as of MIL-100(Fe). However, the crystallinity of ACF@MMIL-100 was noticeably decreased when compared with the unloaded M-MIL-100(Fe). The peak intensities of loaded M-MIL-100(Fe) were reduced while the peak positions in the XRPD patterns were similar for the MIL-100(Fe) and the corresponding unloaded MIL-100(Fe). The XRPD of different structures of M-MIL-100 showed a possible stable framework, which indicates qualitatively ACF loading and the integrity of M-MIL-100(Fe) structures after ACF loading. ${ }^{10}$

Thermal stability of all samples was similar to that of main structure of MIL-100(Fe). The structure collapsed when the temperature was raised to about $580 \mathrm{~K}$ as shown in Figure S1. In addition, the morphological descriptions are shown in Figure S2. It seems that particle size was similar in all samples except in Zn-MIL-100(Fe) samples where the particles were enlarged. This is due to adding $\mathrm{Zn}^{2+}$ to the MIL100(Fe). It seems that zinc salt might lead to slowing down of the nanocrystal nucleation process and growing up of the particles size to be larger specially in the presence of water as a solvent in the synthesis procedure. This is related to the high deliquescent property of zinc nitrate hexahydrate. ${ }^{24,25}$ Although the particle size commonly used for drug delivery was less than $100 \mathrm{~nm}$, the sizes of particles ranged from 100 to $250 \mathrm{~nm}$ are also preferred in drug delivery system. Hence, it can be confirmed that the drug can be delivered to the specific organ or tissue in the desired final dose. ${ }^{26}$ Figure S3 shows that functional groups on the surfaces of the pores were maintained in M-MIL-100(Fe) samples as in MIL-100(Fe).

The $\mathrm{N}_{2}$ adsorption-desorption isotherms for all M-MIL$100(\mathrm{Fe})$ samples are shown in Figure 3. The resultant pore size, surface area, and pore volume are shown in Table 2 . This indicates that the content of a second metal in the final product was varied and dependent on the type of metal. In addition, a lower proportion of the second metal was investigated in the final product in compared to the first metal $\left(\mathrm{Fe}^{3+}\right)$. The nonconjoined metal may affect the pore size, pore volume, and surface area as it can play a prominent role as a template beside the solvent in the synthesis process. Consequently, it can be seen that the isotherms are vertical at pressures close to $1 \mathrm{~atm}$, indicating that all samples had significantly higher pore size and pore volume than MIL-100(Fe). ${ }^{27}$ Specifically, increasing the content of the second metal increased pore volume to at least double that of the parent MIL-100(Fe). The maximum pore volume displayed with Ca II-MIL-100(Fe), Zn I-MIL-100(Fe), and Zn II-MIL-100(Fe) was 1.17, 1, and $1.04 \mathrm{~cm}^{3} / \mathrm{g}$, respectively. In addition, the maximum diameter was doubled in MnI-MIL-100(Fe) and Mn II-MIL-100(Fe). However, the surface area consequently was reduced in M-MIL-100(Fe) $\left(\mathrm{Mn}^{2+}, \mathrm{Mg}^{2+}, \mathrm{Zn}^{2+}\right)$ samples below MIL-100(Fe), while it declined in Ca I-MIL-100(Fe) and increased to $1,848.45 \mathrm{~m}^{2} / \mathrm{g}$ in Ca II-MIL-100(Fe). This can be attributed to that each metal has different coordination environment, different ionic radius, different coordination geometry, and different affinity to exchange by solvent exchange method. When a second metal has different ionic radius, different valence number, and different coordination geometry, it can occupy vacant metal sites in the main metal cluster. ${ }^{28-30}$ Therefore, an increase in the size of ions might lead to increase in lattice disorder. ${ }^{31}$ More specifically, activation by solvent exchange process followed by heating at $433 \mathrm{~K}$ leads to removal of a second metal from the occupied metal site or removal of the whole metal cluster, which increases the structural defects, and consequently the pore volume and size are enhanced. . $^{32,33}$

Hence the successively incorporating a metal ion followed by desolvation can significantly change the textural properties, which in turn can affect the drug adsorption properties. ${ }^{34}$ Significantly, increasing the pore diameter $>2 \mathrm{~nm}$ was observed in all M-MIL-100(Fe) samples; therefore, controlled drug delivery can be enhanced. ${ }^{6}$

The ACF LC and EE were same values because the weights of the M-MIL-100(Fe) and ACF before mixing were equal. The LC and EE showed a significant increment for all M-MIL-100(Fe) samples in comparison to the MIL$100(\mathrm{Fe})$, which is a single metal ion, as shown in Table 2. The ACF LC of MIL-100(Fe) was $27 \%$, whereas the LC of M-MOFs significantly increased to $37 \%$ with Ca I-MIL$100(\mathrm{Fe})$ and more than doubled (57\% and 59\%) when $\mathrm{Mn}$ II-MIL-100(Fe) and Zn II-MIL-100(Fe) were, respectively, employed. These results demonstrated the effects of diversity in the pore and volume sizes and surface area of M-MOFs as shown in Table 2. The type and percentage of a second metal incorporated with an organic linker alongside with the Fe ion have a major role in the modification of the functionalized site in the M-MOF and consequently improving its textural characterization. ${ }^{35}$ The lowest LC of M-MOF was $37 \%$, which occurred with Ca I-MIL-100-(Fe), and that can be related to the lowest pore volume $\left(0.67 \mathrm{~cm}^{3} / \mathrm{g}\right)$ and surface area $\left(1,078.82 \mathrm{~m}^{2} / \mathrm{g}\right)$, while the pore volume and surface area of Ca II-MIL-100(Fe) $\left(1.17 \mathrm{~cm}^{3} / \mathrm{g}\right.$ and $1,848.45 \mathrm{~m}^{2} / \mathrm{g}$, respectively) have demonstrated increased LC (50\%). All other M-MIL-100(Fe) type II demonstrated higher loading capacities of ACF as compared to the type I. This can be related to the increased pore size, pore volume, or surface area of M-MIL-100(Fe), which is the effect of the second metal within MOF. Increasing the pore size or volume can improve the mobility of the drug molecules within the pores by 

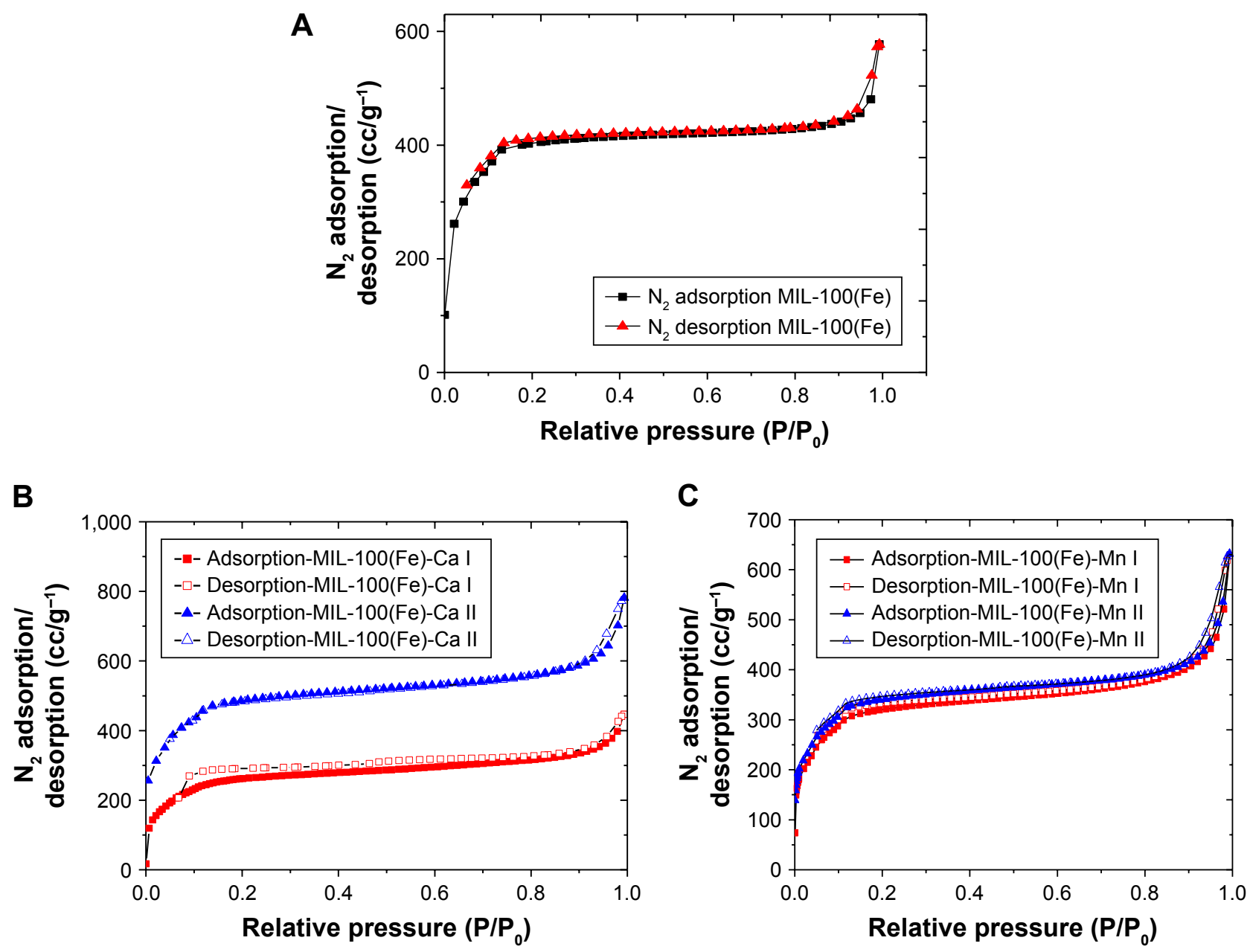

D
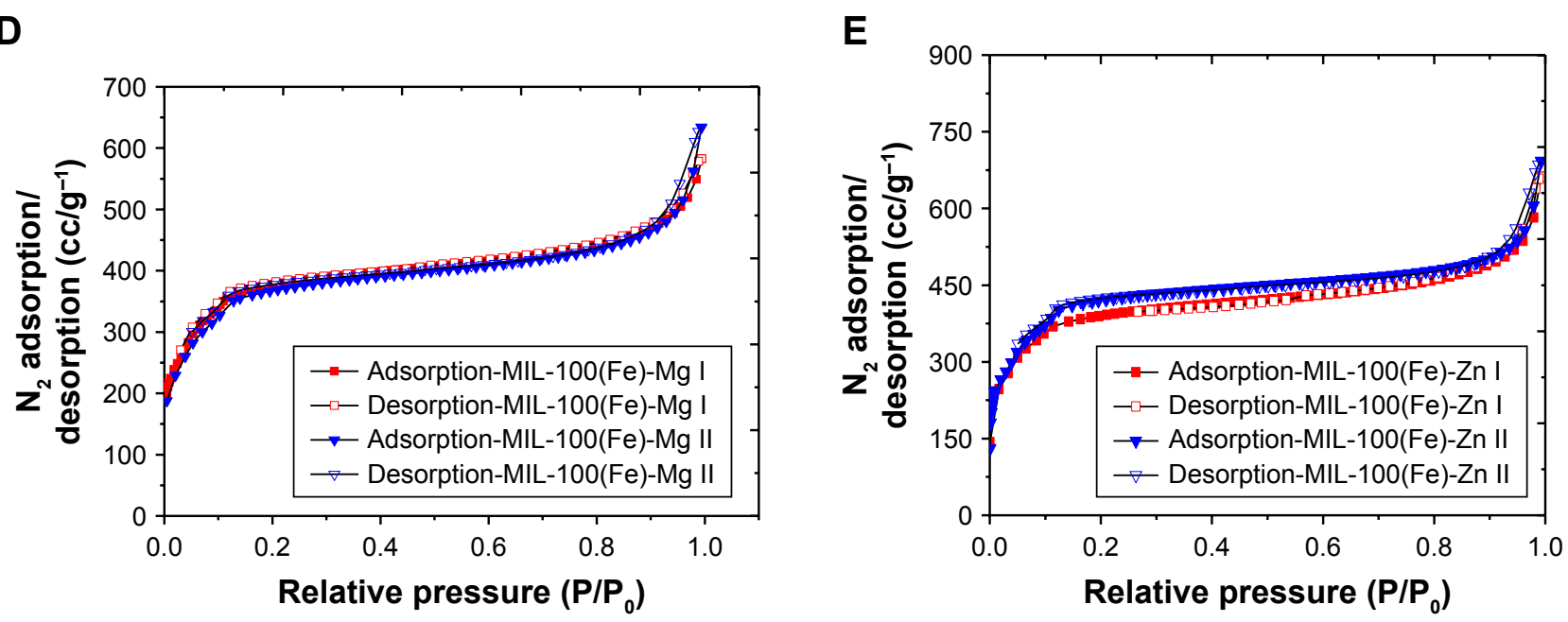

Figure $3 \mathrm{~N}_{2}$ adsorption-desorption isotherms for MIL-100(Fe) (A) and M-MIL-I00(Fe) (M is Ca (B), Mn (C), Mg (D), or Zn (E)) samples.

uniformly increasing the diffusion rate in the case of loading and release of the drug. ${ }^{36}$ The highest ACF LC (59\%) was with Zn II-MIL-100(Fe) owing to the increased pore size and volume and in addition to the surface area of Zn II-MIL-100(Fe) $\left(2.61 \mathrm{~nm}, 1.04 \mathrm{~cm}^{3} / \mathrm{g}\right.$, and $1,590.46 \mathrm{~m}^{2} / \mathrm{g}$, respectively). It was previously shown that MOFs adsorb drastically different amounts of drug as a result of their different pore volumes and pore sizes. ${ }^{6,23}$ No previous study has demonstrated ACF loading with MOF; however, this study shows a significant loading of ACF on MOF while the results in previous report showed 
Table 2 Textural properties of MIL-I00(Fe) and M-MIL-I00(Fe) and loading percentages of ACF

\begin{tabular}{|c|c|c|c|c|c|c|}
\hline MIL & $\begin{array}{l}\text { M/Fe \% final } \\
\text { product }\end{array}$ & $\begin{array}{l}\text { Surface area } \pm \text { SD } \\
\mathrm{m}^{2} / \mathrm{g}\end{array}$ & $\begin{array}{l}\text { Pore size } \pm \text { SD } \\
\text { nm }\end{array}$ & $\begin{array}{l}\text { Pore volume } \pm \text { SD } \\
\mathrm{cm}^{3} / \mathrm{g}\end{array}$ & $\mathbf{L C} \% \pm \mathbf{S D}$ & EE $\% \pm$ SD \\
\hline MIL-I00(Fe) & 0 & $\mathrm{I}, 604 \pm 5.0$ & $1.29 \pm 0.09$ & $0.52 \pm 0.02$ & $27 \pm 1.9$ & $27 \pm 1.9$ \\
\hline Ca I-MIL-I00(Fe) & 0.38 & $1,078 \pm 7.9$ & $2.48 \pm 0.04$ & $0.67 \pm 0.03$ & $37 \pm 2.1$ & $37 \pm 2.1$ \\
\hline Ca II-MIL-I00(Fe) & 1.75 & $1,848 \pm 6.6$ & $2.53 \pm 0.05$ & I. $17 \pm 0.03$ & $50 \pm 2.2$ & $50 \pm 2.2$ \\
\hline Mg I-MIL-I00(Fe) & 0.04 & $1,508 \pm 8.4$ & $2.33 \pm 0.02$ & $0.88 \pm 0.05$ & $47 \pm 1.1$ & $47 \pm 1.1$ \\
\hline Mg II-MIL-I00(Fe) & 0.55 & $1,384 \pm 6.9$ & $2.74 \pm 0.02$ & $0.95 \pm 0.04$ & $5 I \pm 3.3$ & $5 I \pm 3.3$ \\
\hline Mn I-MIL-I00(Fe) & 0.11 & $1,272 \pm 3.0$ & $2.89 \pm 0.04$ & $0.92 \pm 0.01$ & $45 \pm 2.8$ & $45 \pm 2.8$ \\
\hline Mn II-MIL-I00(Fe) & 0.45 & $1,305 \pm 10.0$ & $2.88 \pm 0.07$ & $0.94 \pm 0.06$ & $57 \pm 2.4$ & $57 \pm 2.4$ \\
\hline Zn I-MIL-100(Fe) & 0.07 & 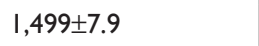 & $2.67 \pm 0.06$ & $1.00 \pm 0.07$ & $49 \pm 1.7$ & $49 \pm 1.7$ \\
\hline Zn II-MIL-100(Fe) & 0.17 & $1,590 \pm 9.9$ & $2.61 \pm 0.06$ & $1.04 \pm 0.04$ & $59 \pm 2.5$ & $59 \pm 2.5$ \\
\hline
\end{tabular}

Abbreviations: ACF, aceclofenac; EE, entrapment efficiency; LC, loading capacity.

that a maximum LC of diclofenac within Zhejiang University (ZJU)-101 MOF was accomplished with a rate up to $\sim 50 \%$. $^{37}$

The NMR analysis showed ACF loading in Figure 4. The loading area is represented by the green labeling, which is located between 6.3 and 7.5 ppm as shown in Figure 4.
Presence of aromatic amide in the ACF molecule has resonance at 7 theta degree, which shows ACF was protonated and refers to the chemical stability of the adsorbed drug in the pores. This spectrum of resonance was same for all loaded M-MIL-100(Fe) samples. ${ }^{38,39}$
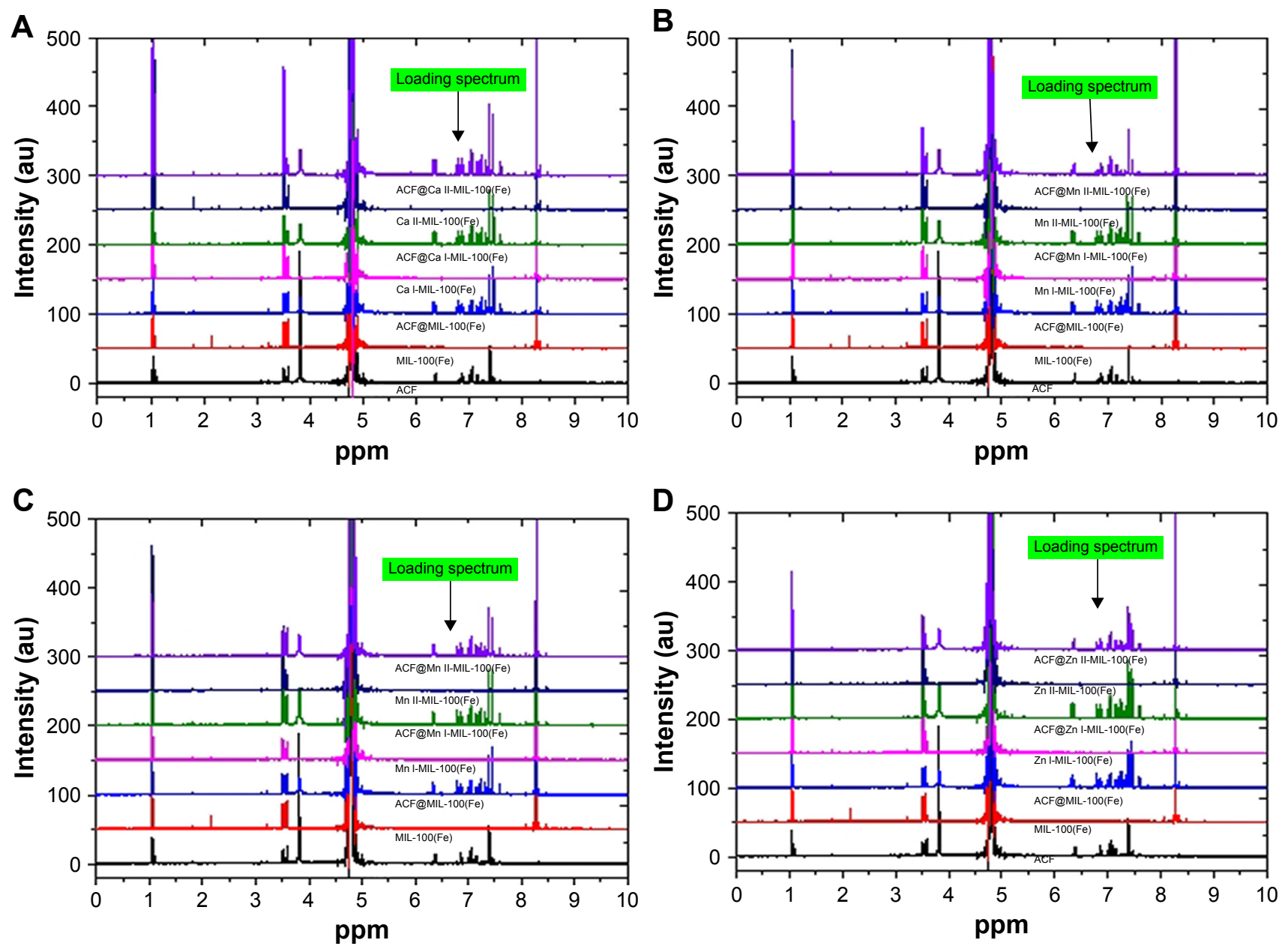

Figure 4 NMR of ACF and corresponding M-MIL-I00(Fe) samples (ACF and Ca-M-MIL-(Fe) I and II) (A), (ACF and Mg-MIL-I00(Fe-) I and II) (B), (ACF and Mn-MIL$\mathrm{I} 00(\mathrm{Fe}) \mathrm{I}$ and II) $(\mathrm{C})$, and (ACF and Zn-MIL-I00(Fe) I and II) (D).

Abbreviations: ACF, aceclofenac; NMR, nuclear magnetic resonance. 
Zeta potential measurements were obtained to confirm the loading event and stability of nanoparticles of M-MIL100(Fe) and ACF@M-MIL-100(Fe) because the surface charge of the particles and binding force types between the molecules of the drug and the nanoparticles are the most important parameters to approve the drug loading efficiency and the release rate of drug. ${ }^{40}$ Zeta potential measurements of ACF@M-MIL-100(Fe) were positively increased in comparison to the bare M-MIL-100(Fe) as shown in Table 3. This result indicated the loading of ACF within M-MIL-100(Fe) and the interaction between carboxyl groups of the organic linker of M-MIL-100(Fe) samples with hydroxyl group of ACF to form ester bond. Therefore, the negativity of the carboxylic group in all M- MIL-100(Fe) samples was reduced although the changes were small. The binding type and the rate of drug loading on the surface of nanoparticles can be determined by the surface charge of the MOF and hydrophobicity of the drug. By measurement of the zetapotential of the MOF before and after loading, one can determine if the drug is adsorbed or not due to electrostatic interaction between charged block of MOF and oppositely charged drug, which has allowed the formation of core-shell, and in this way, loading efficiency will be improved. ${ }^{41}$

The release profiles of ACF were achieved in the simulated GIT and plasma medium of phosphate buffer solutions at either $\mathrm{pH} 6.8$ or 7.4. The ACF release profiles are shown in Figure 5A-D for all ACF@M-MIL-100(Fe) samples.

Table 3 Zeta potential values of all M-MIL-I00(Fe) and ACF@MMIL-I00(Fe)

\begin{tabular}{l|l}
\hline MOF & Zeta potential $(\mathbf{m V}) \pm$ SD \\
\hline MIL-I00(Fe) & $-18.9 \pm 0.2$ \\
ACF@MIL-I00(Fe) & $-12.0 \pm 1.0$ \\
Ca I-MIL-I00(Fe) & $-21.5 \pm 0.8$ \\
ACF@Ca I-MIL-I00(Fe) & $-12.2 \pm 1.1$ \\
Ca II-MIL-I00(Fe) & $-9.97 \pm 0.9$ \\
ACF@Ca II-MIL-I00(Fe) & $-12.6 \pm 0.3$ \\
Mg I-MIL-I00(Fe) & $-14.7 \pm 0.7$ \\
ACF@Mg I-MIL-I00(Fe) & $-12.3 \pm 0.2$ \\
Mg II-MIL-I00(Fe) & $-15.7 \pm 0.7$ \\
ACF@Mg II-MIL-I00(Fe) & $-10.1 \pm 0.9$ \\
Mn I-MIL-I00(Fe) & $-18.5 \pm 0.8$ \\
ACF@Mn I-MIL-I00(Fe) & $-11.7 \pm 1.0$ \\
Mn II-MIL-I00(Fe) & $-19.4 \pm 0.6$ \\
ACF@Mn II-MIL-100(Fe) & $-11.5 \pm 0.5$ \\
Zn I-MIL-I00(Fe) & $-18.1 \pm 0.1$ \\
ACF@Zn I-MIL-I00(Fe) & $-11.8 \pm 0.5$ \\
Zn II-MIL-I00(Fe) & $-18.0 \pm 0.5$ \\
ACF@Zn II-MIL-I00(Fe) & $-13.2 \pm 0.2$ \\
\hline
\end{tabular}

Note: $\pm S D, n=3$.

Abbreviations: ACF, aceclofenac; MOF, metal organic framework.
The release profiles of ACF in both medium demonstrate a slower release-rate profile of ACF@M-MIL-100(Fe) as compared to the ACF@MIL-100(Fe) whether at pH 6.8 or 7.4. There was also a reduction in the release rate in $\mathrm{pH} 6.8$ medium in comparison with 7.4. The release profiles show a difference in the rate of release according to the type of the second metal employed in the M-MIL-100(Fe). Although it was known that the release rate can be enhanced by increasing the pore size ${ }^{42}$ the release of ACF from Zn I-MIL-100(Fe) and II was slower in comparison to others. The total amounts of the ACF released were between 91\% with ACF@MIL$100(\mathrm{Fe})$ and 75\% for ACF@Zn II-MIL-100(Fe) at pH 6.8. The slow release profile at $\mathrm{pH} 6.8$ phosphate buffer medium can be related to the dissolution rate of $\mathrm{ACF}$ at this $\mathrm{pH}$ and the strength of the interaction of ACF within the pores at the surface of M-MOF molecule. ${ }^{43,44}$ The solubility of ACF and consequently its dissolution rate depends on the pKa of ACF (4.7) and the $\mathrm{pH}$ of the medium therefore the release rate of $\mathrm{ACF}$ at $\mathrm{pH} 6.8$ medium was slower as comparison to the $\mathrm{pH}$ 7.4 medium. The slow release of ACF@Zn I-MIL-100(Fe) and $\mathrm{Zn}$ II-MIL-100(Fe) may be related to the competition between the phosphate buffer medium and the strength of interaction of the ACF within the pores of M-MIL-100$(\mathrm{Fe}) .{ }^{45} \mathrm{Also}$, it may be attributed to the partial degradation in the presence of heavier phosphate anions adsorbed on the porous framework. Hence, progressive ACF release from MIL-Fe(100) solid would be mostly governed by a controlled diffusion of the ACF through the slightly amphiphilic pores. The rapid release in the first stage of dissolution process may be related to the slow collapsing of the MOF structure in the phosphate buffer solution with replacement of the carboxylate linkers by phosphate groups. ${ }^{46}$

\section{Conclusion}

The second metal was successfully incorporated with base metal. A low concentration of the second metal was investigated in the final product although a high concentration was used in the synthesis procedure. It seems smaller amounts of the second metal $\left(\mathrm{Ca}^{2+}, \mathrm{Mn}^{2+}, \mathrm{Mg}^{2+}\right.$, and $\left.\mathrm{Zn}^{2+}\right)$ were incorporated in metal center of MIL-100(Fe), and the remaining amount worked as a template. Therefore, the textural properties were improved toward enhancing the pore size and pore volume. The drug LC was doubled in comparison to the bare MIL-100(Fe). The release-rate profile of ACF was promising as a sustained release of the drug. These MOFs have a typical nanoparticle size and high stability with high loading and very good release rate so that they are promising materials for drug delivery systems. 

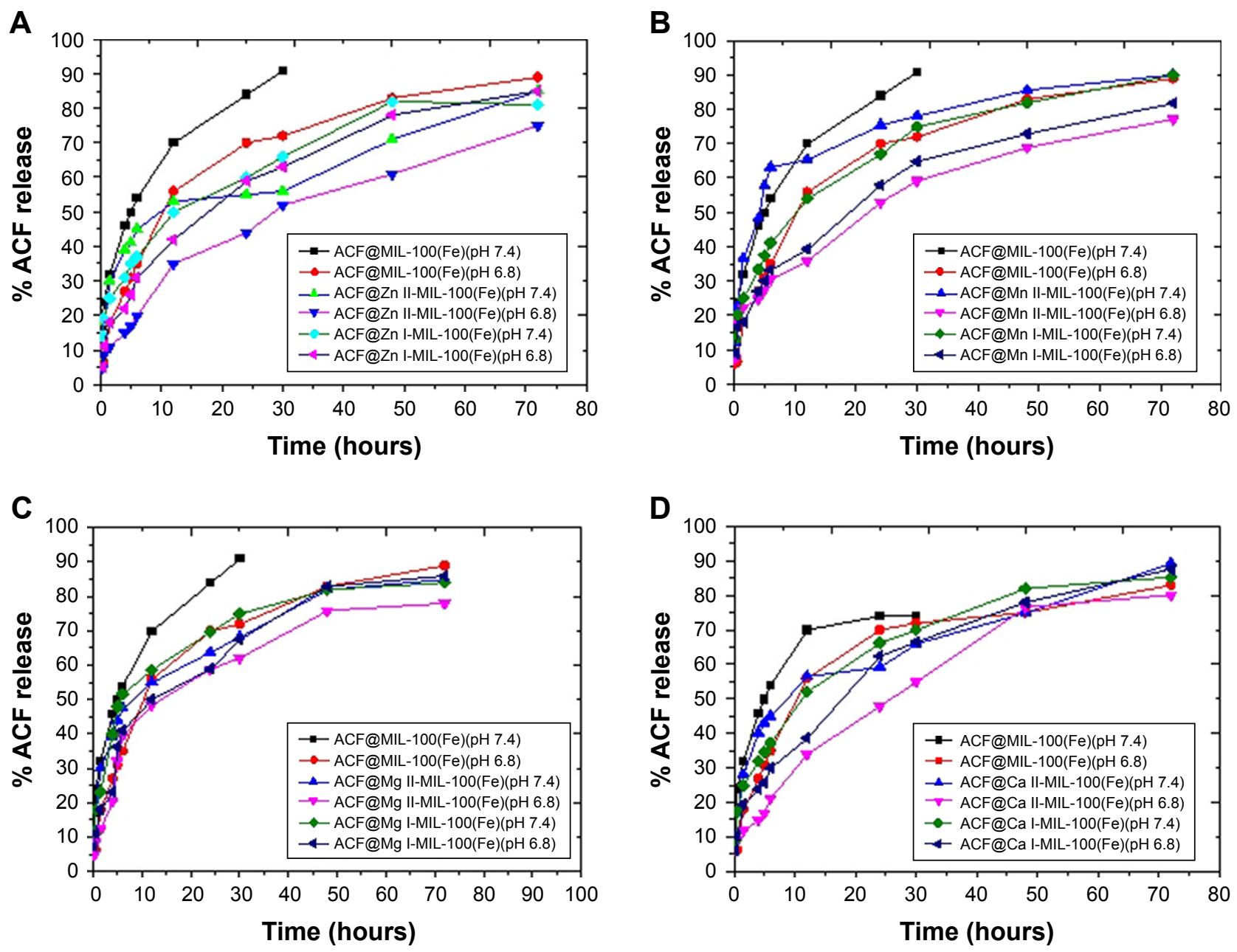

Figure 5 The release profiles of (A-D) represent all ACF@M-MIL-I00(Fe) ( $\mathrm{Zn}, \mathrm{Mn}, \mathrm{Mg}$, and Ca, respectively) samples in $50 \mathrm{mmol}$ phosphate buffer (pH 6.8 and 7.4) at $37^{\circ} \mathrm{C} \pm 1^{\circ} \mathrm{C}$.

Abbreviation: ACF, aceclofenac.

\section{Acknowledgments}

We acknowledge the School of Pharmacy and Faculty of Science and Engineering, Curtin University for providing access to their laboratories and employing different instruments and materials. The authors acknowledge the use of Curtin University's microscopy and microanalysis facilities, whose instrumentation has been partially funded by University, State, and Commonwealth Government.

\section{Disclosure}

The authors report no conflicts of interest in this work.

\section{References}

1. Valizadeh B, Nguyen TN, Stylianou KC. Shape engineering of metalorganic frameworks. Polyhedron. 2018;145:1-15.

2. Furukawa H, Cordova KE, O'Keeffe M, Yaghi OM. The chemistry and applications of metal-organic frameworks. Science. 2013;341(6149): 1230444.
3. Pettinari C, Marchetti F, Mosca N, Tosi G, Drozdov A. Application of metal - organic frameworks. Polym Int. 2017;66(6):731-744.

4. Sun CY, Qin C, Wang XL, Su ZM. Metal-organic frameworks as potential drug delivery systems. Expert Opin Drug Deliv. 2013;10(1): 89-101.

5. Della Rocca J, Liu D, Lin W. Nanoscale metal-organic frameworks for biomedical imaging and drug delivery. Acc Chem Res. 2011;44(10): 957-968.

6. Horcajada P, Serre C, Vallet-Regí M, Sebban M, Taulelle F, Férey G. Metal-organic frameworks as efficient materials for drug delivery. Angew Chem Int Ed Engl. 2006;45(36):5974-5978.

7. Dhakshinamoorthy A, Asiri AM, Garcia H. Mixed-metal or mixedlinker metal organic frameworks as heterogeneous catalysts. Catal Sci Technol. 2016;6(14):5238-5261.

8. Li SY, Liu ZH. Co5In(BTC)4[B2O4(OH)]2: the first MOF material constructed by borate polyanions and carboxylate mixed ligands. Dalton Trans. 2016;45(1):66-69.

9. Fang Z, Bueken B, De Vos DE, Fischer RA. Defect-engineered metal-organic frameworks. Angew Chem Int Ed Engl. 2015;54(25): 7234-7254.

10. Song X, Kim TK, Kim H, et al. Post-synthetic modifications of framework metal ions in isostructural metal-organic frameworks: core-shell heterostructures via selective transmetalations. Chem Mater. 2012; 24(15):3065-3073. 
11. Ahmad N, Younus HA, Chughtai AH, et al. Development of mixed metal metal-organic polyhedra networks, colloids, and MOFs and their pharmacokinetic applications. Sci Rep. 2017;7(1):832.

12. Wu MX, Yang YW. Metal-organic framework (MOF)-based drug/cargo delivery and cancer therapy. Adv Mater. 2017;29(23):1606134.

13. Wang L, Zheng M, Xie Z. Nanoscale metal-organic frameworks for drug delivery: a conventional platform with new promise. J Mater Chem B. 2018;6(5):707-717.

14. Shakeel F, Ramadan W, Shafiq S. Solubility and dissolution improvement of aceclofenac using different nanocarriers. J Bioequiv Availab. 2009;01(02):39-43.

15. Narayan R, Pednekar A, Bhuyan D, Gowda C, Koteshwara KB, Nayak UY. A top-down technique to improve the solubility and bioavailability of aceclofenac: in vitro and in vivo studies. Int J Nanomedicine. 2017;12:4921-4935.

16. Lee B, Jung H. Enhanced bioavailability of poorly water-soluble aceclofenac using PEG-based solid dispersion in rats, beagle dogs and human subjects. AAPS Annual Meeting, New Orleans, LA, USA. Pharm Sci Supplement. 1999:S614-614.

17. Nagda C, Chotai N, Patel S, Nagda D, Patel U, Soni T. Chitosan microspheres of aceclofenac: in vitro and in vivo evaluation. Pharm Dev Technol. 2010;15(5):442-451.

18. Khandai M, Chakraborty S, Nayak P, et al. Preparation and in vitro in vivo evaluation of aceclofenac loaded alginate microspheres: an investigation of effects of polymer using multiple comparison analysis. Curr Drug Deliv. 2012;9(5):495-505.

19. Mutalik S, Anju P, Manoj K, Usha AN. Enhancement of dissolution rate and bioavailability of aceclofenac: a chitosan-based solvent change approach. Int J Pharm. 2008;350(1-2):279-290.

20. Ganesh M, Jeon UJ, Ubaidulla U, et al. Chitosan cocrystals embedded alginate beads for enhancing the solubility and bioavailability of aceclofenac. Int J Biol Macromol. 2015;74:310-317.

21. Rojas S, Colinet I, Cunha D, et al. Toward understanding drug incorporation and delivery from biocompatible metal-organic frameworks in view of cutaneous administration. ACS Omega. 2018;3(3):2994-3003.

22. Sostres C, Gargallo CJ, Arroyo MT, Lanas A. Adverse effects of nonsteroidal anti-inflammatory drugs (NSAIDs, aspirin and coxibs) on upper gastrointestinal tract. Best Pract Res Clin Gastroenterol. 2010;24(2): 121-132.

23. Al Haydar M, Abid HR, Sunderland B, Wang S. Metal organic frameworks as a drug delivery system for flurbiprofen. Drug Des Devel Ther. 2017;11:2685-2695.

24. Zaręba JK, Nyk M, Samoć M. Co/ZIF-8 heterometallic nanoparticles: control of nanocrystal size and properties by a mixed-metal approach. Cryst Growth Des. 2016;16(11):6419-6425.

25. Saliba D, Ammar M, Rammal M, Al-Ghoul M, Hmadeh M. Crystal growth of ZIF-8, ZIF-67, and their mixed-metal derivatives. J Am Chem Soc. 2018;140(5):1812-1823.

26. Orellana-Tavra C, Mercado SA, Fairen-Jimenez D. Endocytosis mechanism of nano metal-organic frameworks for drug delivery. $A d v$ Healthc Mater. 2016;5(17):2261-2270.

27. Abid HR, Rada ZH, Duan X, Sun $\mathrm{H}$, Wang S. Enhanced $\mathrm{CO}_{2}$ adsorption and selectivity of $\mathrm{CO}_{2} / \mathrm{N}_{2}$ on Amino-MIL-53(Al) synthesized by polar co-solvents. Energy Fuels. 2018;32(4):4502-4510.

28. Botas JA, Calleja G, Sánchez-Sánchez M, Orcajo MG. Effect of Zn/Co ratio in MOF-74 type materials containing exposed metal sites on their hydrogen adsorption behaviour and on their band gap energy. Int $J$ Hydrogen Energy. 2011;36(17):10834-10844.
29. Jiao Y, Morelock CR, Burtch NC, Mounfield WP, Hungerford JT, Walton KS. Tuning the kinetic water stability and adsorption interactions of Mg-MOF-74 by partial substitution with Co or Ni. Ind Eng Chem Res. 2015;54(49):12408-12414.

30. Gotthardt MA, Schoch R, Wolf S, Bauer M, Kleist W. Synthesis and characterization of bimetallic metal-organic framework $\mathrm{Cu}-\mathrm{Ru}-\mathrm{BTC}$ with HKUST-1 structure. Dalton Trans. 2015;44(5):2052-2056.

31. Yang $\mathrm{X}, \mathrm{Xu} \mathrm{Q}$. Bimetallic metal-organic frameworks for gas storage and separation. Cryst Growth Des. 2017;17(4):1450-1455.

32. Yuan S, Qin JS, Lollar CT, Zhou HC. Stable metal-organic frameworks with group 4 metals: current status and trends. ACS Cent Sci. 2018;4(4):440-450.

33. Yuan L, Tian M, Lan J, et al. Defect engineering in metal-organic frameworks: a new strategy to develop applicable actinide sorbents. Chem Commun (Camb). 2018;54(4):370-373.

34. Yuan S, Qin JS, Li J, et al. Retrosynthesis of multi-component metalorganic frameworks. Nat Commun. 2018;9(1):808.

35. Vuong GT, Pham MH, Do TO. Synthesis and engineering porosity of a mixed metal Fe2Ni MIL-88B metal-organic framework. Dalton Trans. 2013;42(2):550-557.

36. Vallet-Regí M, Balas F, Arcos D. Mesoporous materials for drug delivery. Angew Chem Int Ed Engl. 2007;46(40):7548-7558.

37. Li W, Zhang Y, Zhang C, et al. Transformation of metal-organic frameworks for molecular sieving membranes. Nat Commun. 2016;7:11315.

38. Hussain MA, Zarish A, Abbas K, et al. Hydroxypropylcelluloseaceclofenac conjugates: high covalent loading design, structure characterization, nano-assemblies and thermal kinetics. Cellulose. 2013; 20(2):717-725

39. Krajnc A, Kos T, Zabukovec Logar N, Mali G. A simple NMR-based method for studying the spatial distribution of linkers within mixed-linker metal-organic frameworks. Angew Chem Int Ed Engl. 2015;54(36): $10535-10538$

40. Honary S, Zahir F. Effect of zeta potential on the properties of nanodrug delivery systems-a review (Part 1). Tropical J Pharmaceut Res. 2013;12(2):255-264.

41. Honary S, Zahir F. Effect of zeta potential on the properties of nano-drug delivery systems-a review (Part 2). Tropical J Pharmaceut Res. 2013; 12(2):265-273.

42. Manaia EB, Abuçafy MP, Chiari-Andréo BG, Silva BL, Oshiro Junior JA, Chiavacci LA. Physicochemical characterization of drug nanocarriers. Int J Nanomed. 2017;12:4991-5011.

43. Deshmukh RK, Naik JB. The impact of preparation parameters on sustained release aceclofenac microspheres: a design of experiments. Adv Powder Technol. 2015;26(1):244-252.

44. Aerts CA, Verraedt E, Mellaerts R, et al. Tunability of pore diameter and particle size of amorphous microporous silica for diffusive controlled release of drug compounds. J Phys Chem C. 2007;111(36): 13404-13409.

45. Xu W, Riikonen J, Lehto VP. Mesoporous systems for poorly soluble drugs. Int J Pharm. 2013;453(1):181-197.

46. Li X, Lachmanski L, Safi S, et al. New insights into the degradation mechanism of metal-organic frameworks drug carriers. Sci Rep. 2017; 7(1):13142.

47. Sun K, Li L, Yu X, et al. Functionalization of mixed ligand metal-organic frameworks as transport vehicles for drugs. J Colloid Interface Sci. 2017;486:128-135. 


\section{Supplementary materials}

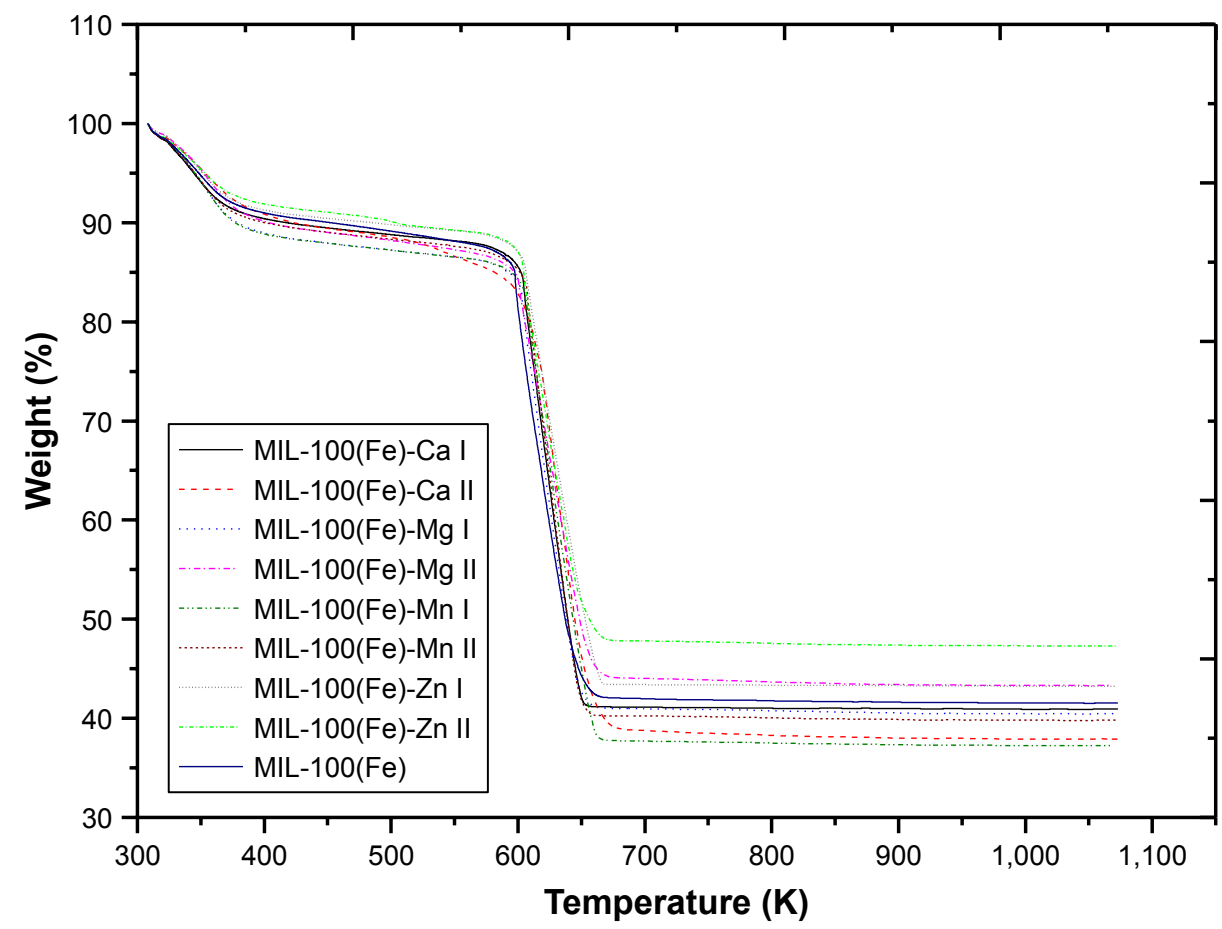

Figure SI TGA profiles of M-MIL-100(Fe) (where M is either $\mathrm{Ca}, \mathrm{Mg}$, Mn, or $\mathrm{Zn}$ ). 

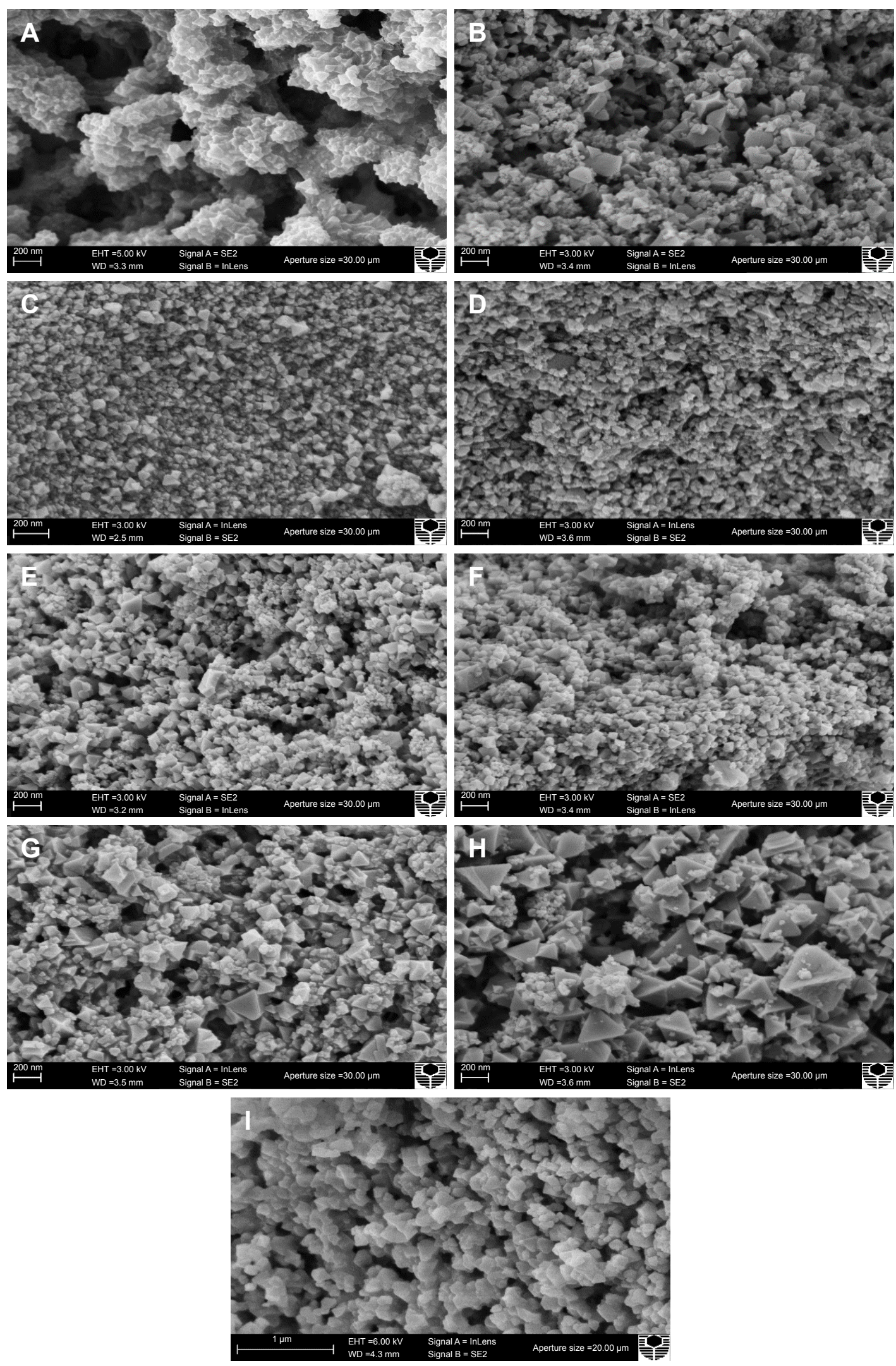

Figure S2 SEM images of MIL-100(Fe) and all M-MILs- $100(\mathrm{Fe})$

Notes: Ca I-MIL-100(Fe) (A), Ca II-MIL-100(Fe) (B), Mg I-MIL-100(Fe) (C), Mg II-MIL-100(Fe) (D), Mn I-MIL-100(Fe) (E), Mn II-MIL-100(Fe) (F), Zn I-MIL-100(Fe) (G), Zn II-MIL-I00(Fe) (H), and MIL-I00(Fe) (I). 


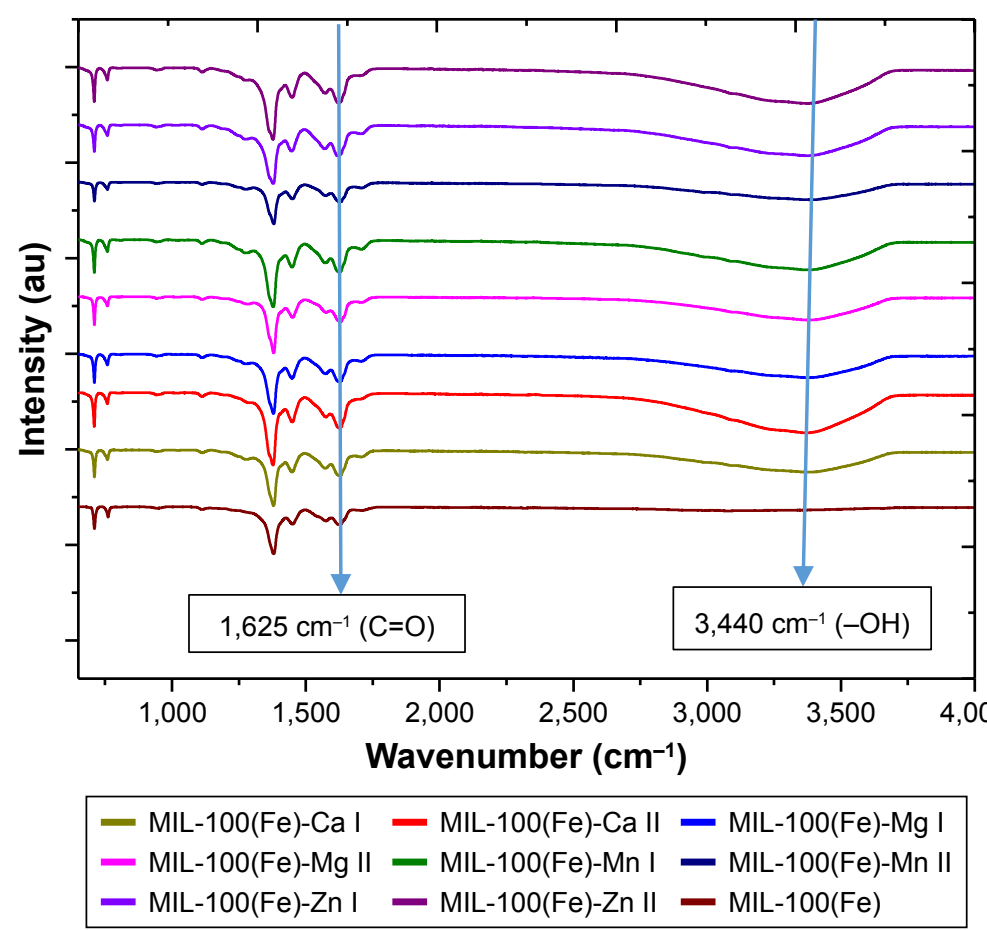

Figure S3 FTIR spectra for M-MIL-I00(Fe) (where M is either $\mathrm{Ca}, \mathrm{Mn}, \mathrm{Mg}$, or $\mathrm{Zn}$ ) samples.

Abbreviation: FTIR, Fourier transform infrared.

\section{Publish your work in this journal}

Drug Design, Development and Therapy is an international, peerreviewed open-access journal that spans the spectrum of drug design and development through to clinical applications. Clinical outcomes, patient safety, and programs for the development and effective, safe, and sustained use of medicines are the features of the journal, which has also been accepted for indexing on PubMed Central. The manuscript management system is completely online and includes a very quick and fair peer-review system, which is all easy to use. Visit http://www.dovepress.com/testimonials.php to read real quotes from published authors.

Submit your manuscript here: http://www.dovepress.com/drug-design-development-and-therapy-journal 